\title{
Essence of locus of control and loneliness on online flow, depression, subjective happiness and satisfaction with life
}

\author{
Soma Parija*, Asmita Shukla \\ School of Humanities, Social Sciences and Management, Indian Institute of Technology Bhubaneswar, India \\ Email address: \\ somaparija85@gmail.com (S. Parija),asmitas@gmail.com (A. Shukla)
}

\section{To cite this article:}

Soma Parija, AsmitaShukla. Essence of Locus of Control and Loneliness on Online Flow, Depression, Subjective Happiness and Satisfaction with Life. American Journal of Applied Psychology. Vol. 2, No. 5, 2013, pp. 52-58. doi: 10.11648/j.ajap.20130205.11

\begin{abstract}
This empirical study demonstrates locus of control and loneliness as important variables predicting online flow experience, depression, subjective happiness and satisfaction with life. Locus of control was categorized into two categories, namely high (external locus of control) and low (internal locus of control). Similarly loneliness was also categorized into high and low loneliness. Data was collected from 342 participants (184 males and 158 females) using a structured questionnaire that contained all the variables of the study. Statistical techniques such as reliability and multivariate analysis of variance (MANOVA) were used to analyze the data. Results revealed significant main effects of locus of control and loneliness on online flow experience, depression, subjective happiness and satisfaction with life. External locus of control and loneliness had a positive effect on online flow experience and depression, and a negative effect on subjective happiness and satisfaction with life. Interaction effects indicated that an individual has high online flow experience and high depression, and low subjective happiness when he/she has external locus of control and suffers from high loneliness. But the interaction effect of locus of control and loneliness on satisfaction with life was insignificant. The limitations, future directions and details of findings of the study have been suitably discussed.
\end{abstract}

Keywords: Personality, Loneliness, Online Flow Experience, Depression, Subjective Happiness, Satisfaction with Life

\section{Introduction}

The explosive growth of internet technology and of internet users over the past decade or so has created a new virtual world altogether. . Internet had been invented in the late 70 's to simplify people's lives and fasten communication. Internet users were perceived as information seekers and the phrase 'to browse' the net was introduced. In the late 1990's, with the advent of the World Wide Web, internet created newer markets and opened portals to global markets in general. But internet and human civilization witnessed a revolution of sorts only in 2000's. The general online flow experience is found at increased levels where a particular individual is lonely and has an external locus of control believing in chance, luck and external stimulus to guide and direct his life decisions. Loneliness is an unpleasant feeling and a subjective experience in which a person experiences a strong sense of emptiness and solitude resulting from inadequate levels of social relationships plays a role in an individual's use of the internet [1]. Such indi- viduals who has an external locus of control and higher degree of loneliness, as this study explores, has high online flow experience and depression, and low subjective happiness and satisfaction with life.

\section{Theoretical Background}

\subsection{Locus of Control}

Locus of control structure shows a distribution on dimensions of internal-external locus of control in a way it was bound to individual perceives degree of their own responsibilities for events [2]. This orientation is related to depression. Depression is a mood disorder in which individuals experience extreme unhappiness, lack of energy, and several related symptoms (DSM - IV). Reference [3] assessed the association between locus of control and depression among Turkish university students and found that external locus of control positively correlated with depression. Reference [4] examined the rural pregnant women to assess their locus of control and prenatal depression. Re- 
sults from multiple regression analysis showed that external locus of control accounted for depression. There also exists a relationship between internal-external locus of control and subjective well-being of people. Subjective happiness is defined as a mental state of well-being characterized by positive emotions ranging from contentment to intense joy [5]. The relationship between happiness and locus of control were explored [6]. Results indicated that there was a significant positive relationship between internal locus of control and subjective happiness. Reference [7] examined the relationship between locus of control and subjective well-being of youth. Internals were found to have higher subjective happiness and satisfaction with life than the externals. Satisfaction with life is an overall assessment of feelings and attitudes about one's life at a particular point in time ranging from negative to positive [8]. Reference [9] studied the aged people and demonstrated through regression analysis that internal locus of control significantly predicts life satisfaction. The relationship between online flow and personality variables was studied [10]. An individual's action in the flow state is experienced as "the holistic sensation that people feel when they act with total involvement" [11]. Reference [12] define flow as "the state occurring during network navigation which is: 1) characterized by a seamless sequence of responses facilitated by machine interactivity, 2) intrinsically enjoyable, 3) accompanied by a loss of self-consciousness, and 4) self-reinforcing." The study gathered data from individuals who were already using the Internet [13]. Results demonstrated that the higher the individual is addicted to the Internet, the less faith the individual has on himself, and has more belief on external power, and has higher trust on chance in determining his own actions. It indicated that there existed a positive relationship between external locus of control and Internet use.

\subsection{Loneliness}

Loneliness can affect people at any time and for some it can be an overwhelming feeling leading to negative thoughts and feelings [14]. They found that loneliness and depression were associated with each other. Reference [15] examined the prevalence of loneliness and depression among different age groups and found out an association of depression and loneliness for all age groups. Reference [16] examined the elderly population and assessed their level of loneliness and depression. The results showed a positive correlation between loneliness and depression in the elderly population. The variable, loneliness has an influence on subjective happiness. They were found to be negatively correlated [17]. Reference [18] examined the older population and demonstrated that loneliness was negatively correlated with happiness. Loneliness was associated with low satisfaction with life [19]. Adolescents who felt lonely were dissatisfied with their lives [20]. Reference [21] assessed loneliness and satisfaction with life in middle-aged Spanish women. Regression analysis reported that higher loneliness correlated with lower life satisfaction. The concept of the "flow experience" also describes a significant coping mechanism for people undergoing solitary ordeals [22]. Reference [23] reported that loneliness was positively correlated with the time spent online in chat rooms. Reference [24] also assessed the association between loneliness and the duration of internet usage. Results showed that loneliness was positively correlated with Internet usage.

\section{Research Gap}

According to many recent studies, personality variables as well as loneliness play an important role on online flow experience, depression, subjective happiness and satisfaction with life. Although past studies have proposed that locus of control and loneliness has a direct influence on depression, subjective happiness and satisfaction with life in different context; to the best of our knowledge, no research has been carried out to examine the interaction effects of locus of control and loneliness on depression, subjective happiness and satisfaction with life. Studies have also tried to find out the relationship between locus of control, depression and internet usage. But no scholarly effort has been made to study the main effects of locus of control and loneliness independently on online flow experience and interaction effect of locus of control and loneliness on online flow experience. So a modified model based on the literature is proposed to fill the research gap.

\section{Proposed Conceptual Framework}

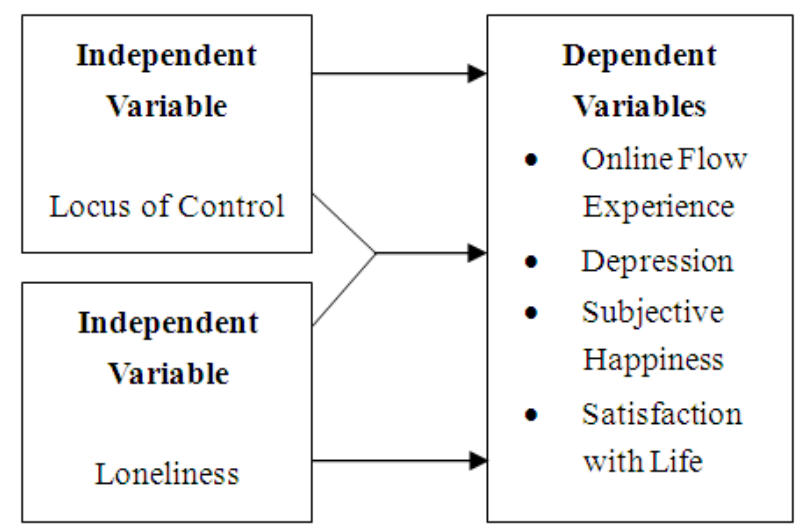

Figure 1. Analysis Framework for Interaction between Locus of Control and Loneliness

\section{Objectives}

The specific research objectives of this study are as follows:

1. To examine whether locus of control determine online flow experience, depression, subjective happiness and satisfaction with life.

2. To examine whether loneliness determine online flow experience, depression, subjective happiness and satisfaction with life. 
3. To examine whether locus of control and loneliness interact with each other to effect online flow experience, depression, subjective happiness and satisfaction with life.

\section{Hypotheses}

The following hypotheses are proposed for the present research:

H1a: The higher the individual is on external locus of control and lower is on internal locus of control, the higher would be his/her online flow experience.

$\mathrm{H} 1 \mathrm{~b}$ : The higher the individual is on external locus of control and lower is on internal locus of control, the higher would be his/her depression.

H1c: The higher the individual is on external locus of control and lower is on internal locus of control, the lower would be his/her subjective happiness.

H1d. The higher the individual is on external locus of control and lower is on internal locus of control, the lower would be his/her satisfaction with life.

$\mathrm{H} 2 \mathrm{a}$ : The higher the individual is on loneliness, the higher would be his/her online flow experience.

$\mathrm{H} 2 \mathrm{~b}$ : The higher the individual is on loneliness, the higher would be his/her depression.

$\mathrm{H} 2 \mathrm{c}$ : The higher the individual is on loneliness, the lower would be his/her subjective happiness.

$\mathrm{H} 2 \mathrm{~d}$. The higher the individual is on loneliness, the lower would be his/her satisfaction with life.

H3a: The higher the individual is on external locus of control and loneliness, the higher would be his/her online flow experience.

$\mathrm{H} 3 \mathrm{~b}$ : The higher the individual is on external locus of control and loneliness, the higher would be his/her depression.

$\mathrm{H} 3 \mathrm{c}$ : The higher the individual is on external locus of control and loneliness, the lower would be his/her subjective happiness.

H3d: The higher the individual is on external locus of control and loneliness, the lower would be his/her satisfaction with life.

\section{Methodology}

The methodology used for carrying out the research work includes the research design, the participants, the measures and procedure used for data collection.

\subsection{Research Design}

A 2(locus of control) X 2(loneliness) between subjects factorial design employing 4 treatment combination was used where there were two categories of locus of control (High: $\mathrm{H}$ - external locus of control and Low: L - internal locus of control) and two categories of loneliness (High: $\mathrm{H}$ and Low: L).

\subsection{Participants}

Three hundred and forty two valid questionnaires were obtained from the survey in India. It included one hundred and eighty four males and one hundred and fifty eight females. Age range of one hundred and twenty six participants were of 18-24 age range, one hundred and nine were of 25-34 years of age, fifty eight participants were 35-44 years of age, thirty were of 45-54 years of age and nineteen participants were 55-64 years of age. The sample comprised one hundred and thirteen students, fifty eight software professionals, thirty four academicians, forty nine bankers, forty five corporate executives, twenty five housewives and eighteen were from other occupations.

\subsection{Measures}

The items used to measure the variables were taken from existing standardized scales as per the need of the study. A description of the measures used in the present study is given below.

\subsubsection{Locus of Control}

The thirteen-item scale of locus of control was adapted from Rotter's Locus of Control Scale developed by Rotter (1966). It measures generalized expectancies for external versus internal control of reinforcement. A high score indicates an external control while a low score indicates internal control.

\subsubsection{Loneliness}

The six-item scale of loneliness was adapted from Gierveld and Tilburg (2006). This scale measures the overall loneliness of an individual. The items were measured on a 6-point Likert Scale ranging from 'very strongly disagree' (1) to 'very strongly agree' (6). A high score indicates higher loneliness and a low score indicates lower loneliness.

\subsubsection{Online Flow Experience}

The seventeen-item scale of online flow experience was adapted from Novak and Hoffman (2003). The items were measured on a 6-point Likert Scale. A high score indicates higher online flow experience and a low score indicates lower online flow experience.

\subsubsection{Depression}

The twenty-item scale of depression was adapted from Zung Self-Rating Depression Scale, designed by Zung (1965) to assess the level of depression for individuals. There are ten positively worded and ten negatively worded questions. The items were measured on a 6-point Likert Scale ranging from 'never' (1) to 'always' (6). A higher score indicates higher level of depression and a lower score indicates a lower level of depression.

\subsubsection{Subjective Happiness}

The four-item scale of subjective happiness was adapted from Subjective Happiness Scale (SHS), developed by 
Lyubomirsky (1997). The items were measured on a 6-point Likert Scale. A higher score indicates higher subjective happiness and a lower score indicates lower subjective happiness.

\subsubsection{Satisfaction with Life}

The five-item scale of satisfaction with life was adapted from Satisfaction with Life Scale (SWLS), developed by Diener, Emmons, Larsen and Griffin (1985). SWLS is a global measure of life satisfaction. The items were measured on a 6-point Likert Scale ranging from 'very strongly disagree' (1) to 'very strongly agree' (6). A high score indicates higher life satisfaction and a low score indicates lower life satisfaction.

Cronbach's alpha was computed to examine the reliability of the measures employed in the study. The cronbach's alpha reliability of the measures is given in Table 1. It showed that the coefficient of internal consistency (Cronbach's alpha) for the items of the measures for the sample of the study was found to be acceptable.

Table 1. Cronbach's Alpha Reliability of the Measures of the Study

\begin{tabular}{lcc}
\hline & Reliability & Number of items \\
\hline Independent Variables & .68 & 13 \\
Locus of Control & .98 & 6 \\
Loneliness & & \\
Dependent Variables & .98 & 17 \\
Online Flow Experience & .99 & 20 \\
Depression & .95 & 4 \\
Subjective Happiness & .96 & 5 \\
Satisfaction with Life & & \\
\hline
\end{tabular}

\subsection{Procedure}

Data was collected through both online and offline method of data collection using a questionnaire that comprises questions seeking information about demographics of the respondents namely name, gender, age, educational level, occupation, name of the company/organization/institution and email. Then it included questions on independent variables (locus of control and loneliness) and the dependent variables (online flow experience, depression, subjective happiness and satisfaction with life) of the study.

The participants of this study $(\mathrm{N}=342)$ were categorized into high and low on locus of control and loneliness on the basis of their mean scores. The mean scores are shown in Table 2 and the number of participants per category is shown in Table 3.

Table 2. Mean Scores

\begin{tabular}{cc}
\hline & Mean Score \\
\hline Locus of Control & 6.87 \\
Loneliness & 23.92 \\
\hline
\end{tabular}

Table 3. Categorization of the Participants on the basis of Mean Score

\begin{tabular}{cccc}
\hline \multicolumn{4}{c}{ Categories } \\
\hline & High & Low & Total \\
Locus of Control & 189 & 153 & 342 \\
Loneliness & 221 & 121 & 342 \\
\hline
\end{tabular}

\section{Results and Interpretation}

Multivariate analysis of variance (MANOVA) was computed to explore the main and interaction effects of locus of control and loneliness on online flow experience, depression, subjective happiness and satisfaction with life. Analysis was carried out using SPSS v.18.

\subsection{Main Effects}

Hypotheses 1 deal with the main effects of locus of control on individual's online flow experience, depression, subjective happiness and satisfaction with life. H1 stated that higher the individual is on locus of control (external locus of control), the higher would be his/her online flow experience (H1a), depression (H1b), subjective happiness (H1c) and satisfaction with life (H1d).

Table 4. Summary of Results of MANOVA of Locus of Control on Online Flow Experience, Depression, Subjective Happiness and Satisfaction with Life

\begin{tabular}{lcccc}
\hline Variables & df & MS & F & १р2 \\
\hline \multicolumn{2}{l}{ Locus of Control } & & & \\
OFE & 1 & 86.37 & $101.45^{*}$ & .23 \\
DEP & 1 & 24.44 & $42.42^{*}$ & .11 \\
SH & 1 & 117.40 & $134.12^{*}$ & .28 \\
SWL & 1 & 28.23 & $33.70^{*}$ & .09 \\
\hline
\end{tabular}

$\mathrm{N}=342, * \mathrm{p}<.05$, OFE $=$ Online Flow Experience, $\mathrm{DEP}=$ Depression, $\mathrm{SH}=$ Subjective Happiness and SWL $=$ Satisfaction with Life

The results indicated significant main effects of locus of control on online flow experience, depression, subjective happiness and satisfaction with life (Table 4), thus H1 (a-d) were accepted.

Hypotheses 2 deal with the main effects of loneliness on individual's online flow experience, depression, subjective happiness and satisfaction with life. $\mathrm{H} 2$ stated that higher the individual is on loneliness, the higher would be his/her online flow experience (H2a), depression ( $\mathrm{H} 2 \mathrm{~b})$, subjective happiness (H2c) and satisfaction with life (H2d).

Table 5. Summary of Results of MANOVA of Loneliness on Online Flow Experience, Depression, Subjective Happiness and Satisfaction with Life

\begin{tabular}{lcccc}
\hline \multicolumn{1}{c}{ Variables } & df & MS & F & пр2 \\
\hline Loneliness & & & & \\
OFE & 1 & 200.37 & $235.54^{*}$ & .41 \\
DEP & 1 & 333.55 & $578.96^{*}$ & .63 \\
SH & 1 & 138.17 & $157.85^{*}$ & .32 \\
SWL & 1 & 245.54 & $293.13^{*}$ & .46 \\
\hline
\end{tabular}

$\mathrm{N}=342, * \mathrm{p}<.05$, OFE $=$ Online Flow Experience, $\mathrm{DEP}=$ Depression, $\mathrm{SH}=$ Subjective Happiness and SWL $=$ Satisfaction with Life 
The results indicated significant main effects of loneliness on online flow experience, depression, subjective happiness and satisfaction with life (Table 5), thus H2 (a-d) were accepted.

\subsection{Interaction Effects}

$\mathrm{H} 3 \mathrm{a}, \mathrm{H} 3 \mathrm{~b}, \mathrm{H} 3 \mathrm{c}$ and $\mathrm{H} 3 \mathrm{~d}$ deal with the interaction effects of locus of control and loneliness on online flow experience, depression, subjective happiness and satisfaction with life. It was hypothesized that the higher the individual is on locus of control (external locus of control) and loneliness, the higher would be his/her online flow experience (H3a) and depression (H3b); and lower would be his/her subjective happiness $(\mathrm{H} 3 \mathrm{c})$ and satisfaction with life (H3d).

Table 6. Summary of Results of MANOVA of the Interaction Effects of Locus of Control and Loneliness on Online Flow Experience, Depression, Subjective Happiness and Satisfaction with Life

\begin{tabular}{|c|c|c|c|c|}
\hline Variables & df & MS & $\mathbf{F}$ & $\eta p 2$ \\
\hline \multicolumn{5}{|c|}{ Locus of Control * Loneliness } \\
\hline OFE & 1 & 200.37 & $27.92 *$ & .07 \\
\hline DEP & 1 & 333.55 & $47.17^{*}$ & .12 \\
\hline SH & 1 & 138.17 & $3.65^{*}$ & .01 \\
\hline SWL & 1 & 245.54 & .62 & .00 \\
\hline \multicolumn{5}{|l|}{ Error } \\
\hline OFE & 338 & .85 & & \\
\hline DEP & 338 & .58 & & \\
\hline SH & 338 & .88 & & \\
\hline SWL & 338 & .84 & & \\
\hline
\end{tabular}

$\mathrm{N}=342,{ }^{*} \mathrm{p}<.05$, OFE $=$ Online Flow Experience, $\mathrm{DEP}=$ Depression, $\mathrm{SH}=$ Subjective Happiness and SWL $=$ Satisfaction with Life

The interaction effects of locus of control and loneliness are shown in Table 6 . The results revealed significant interaction effects of locus of control and loneliness on online flow experience, depression and subjective happiness which supported the hypotheses $\mathrm{H} 3 \mathrm{a}, \mathrm{H} 3 \mathrm{~b}$ and $\mathrm{H} 3 \mathrm{c}$. However, the interaction effect was not found to be significant for satisfaction with life. Therefore H4c was not supported.

The results also revealed that if an individual is high on locus of control (external locus of control) and loneliness, the means of online flow experience and depression were highest, and the mean of subjective happiness was lowest than any other categories of locus of control and loneliness. The means for the categories of locus of control and loneliness on online flow experience, depression and subjective happiness are given in Table 7 to 9. Therefore, hypotheses $\mathrm{H} 3 \mathrm{a}, \mathrm{H} 3 \mathrm{~b}$ and $\mathrm{H} 3 \mathrm{c}$ were supported.

Table 7. Means of Categories of Locus of Control and Loneliness on Online Flow Experience

\begin{tabular}{lcc}
\hline \multicolumn{3}{c}{ Mean Scores for Categories } \\
\hline & Loneliness (High) & Loneliness (Low) \\
Locus of Control (High) & 4.68 & 2.40 \\
Locus of Control (Low) & 2.98 & 1.87 \\
\hline
\end{tabular}

Table 8. Means of Categories of Locus of Control and Loneliness on Depression

\begin{tabular}{lcc}
\hline \multicolumn{3}{c}{ Mean Scores for Categories } \\
\hline & Loneliness (High) & Loneliness (Low) \\
Locus of Control (High) & 4.32 & 1.51 \\
Locus of Control (Low) & 3.11 & 1.55 \\
\hline
\end{tabular}

Table 9. Means of Categories of Locus of Control and Loneliness on Subjective Happiness

\begin{tabular}{lcc}
\hline \multicolumn{3}{c}{ Mean Scores for Categories } \\
\hline & Loneliness (High) & Loneliness (Low) \\
Locus of Control (High) & 2.71 & 4.33 \\
Locus of Control (Low) & 4.22 & 5.41 \\
\hline
\end{tabular}

\section{Discussion and Conclusion}

The present study is an intense attempt to explore empirically the integrative role of personality variable, locus of control and loneliness in determining the online behavior of individuals as well as their level of depression, subjective happiness and satisfaction with life.

Results of MANOVA indicated that external locus of control had a positive effect on online flow experience and depression, and a negative effect on subjective happiness and satisfaction with life. These results are also consistent with earlier findings. People with external locus of control rely on external controlling variables, like luck or fate, for everything that happens to them and this leads to a feeling of helplessness over one's own circumstances. Given this state of mind, people with external locus of control often find themselves actively pursuing a virtual lifestyle. Therefore, such people tend to have a higher online flow experience. Such people are prone to higher incidences of depression owing to their inability to control their own circumstances, especially those circumstances which seem unsatisfactory or unfavorable to them. These people also have a sense of lower satisfaction and subjective happiness in life as they tend to rely on external variables like destiny or fate to change the unsatisfactory circumstances they are in, and finding themselves unable to help their own situation, tends to push them towards a general sense of dissatisfaction towards life and a lowered subjective happiness.

The results of the present research also revealed that loneliness had a positive effect on online flow experience and depression. And it was found to have a negative effect on subjective happiness and satisfaction with life. The results are consistent with earlier findings. Individuals who characterize themselves as lonely or tend to spend most of their time alone would be prone to higher rates of depression as their seclusion from the extraneous social factors leads to inhibitions about oneself, which causes a person to be occupied with one's own self to the extent that it prohibits them from successfully socializing with other people. This form of social and psychological isolation coupled with the constant preoccupation with oneself, makes lonely people 
more prone to dwell on their personal flaws and lacunae which would eventually lead to higher rates of depression amongst lonely people. Man being a gregarious animal by nature, isolation from extraneous social elements which is a characteristic of loneliness, also invariably leads to a lower subjective happiness and satisfaction with life resulting from the lack of social interaction with other human beings which a lonely person subjects him or herself to. The virtual social interactions and experience of these lonely people serves as a form of redemption for all the lack of social interactions and the seclusion of their real lives from extraneous social variables. The internet simulates social interaction through social media, instant messaging and other such features, which allow such individuals to have a constructed sense of socializing with other people without physical proximity or exposure. Therefore, they have higher online flow experience.

The interactive role of locus of control and loneliness was also evident in the results which imply that when an individual's external locus of control will increase and his/her loneliness will also increase at the same time, then his/her level of depression will increase further and subjective happiness will be deteriorated. At the same time the individual's online flow experience will also be enhanced as these individuals will spend more time online rather than offline. But results found out that satisfaction with life was not hampered when the individual was externally controlled and a high degree of loneliness. Thus it can be said that the higher the individual is on external locus of control and loneliness, the higher would be his/her depression and online flow experience and lower would be his/her subjective happiness. The estimated marginal means show that individuals who are high on external locus of control $(\mathrm{H})$ and higher on loneliness $(\mathrm{H})$ has higher online flow experience and depression, and lower subjective happiness (online flow experience $($ mean $)=4.68$, depression $($ mean $)=$ 4.32 and subjective happiness $($ mean $)=2.71$ ). The external locus of control which feeds on the social interactions is affected by the lack of social interaction induced by loneliness, thereby adding to the depression. Further, the online flow experience tends to supplement the extraneous feedback derived from customizing one's virtual personality and world through social media and such other tools, which in turn reduces the feeling of helplessness over one's circumstances, which is common with people having external locus of control, thereby enhancing the subjective happiness. However, since this is a temporary respite, this extraneous virtual feedback cannot sustain the need for the external locus of control, which may be the reason why the increase in satisfaction with life is not significant in such individuals.

Finally, we can conclude that the individuals who have an external locus of control and are lonely are normally in a constant state of depression and feel left out. So, their subjective well-being gets affected resulting in lowered happiness and satisfaction with life. They prefer to stay back and let other people take the lead in a social gathering. They prefer to be lonely than to be cause for any embarrassment to the group. It was observed that these individuals post increased online flow experience improved on their state of subjective happiness and felt less depressed and lonely. This reflected even in their social outlook and performance. They found it easier to be part of a conversation without feeling awkward. Even though they are not the center of attraction but they found themselves starting to belong. They started to uphold their end of a conversation. Knowing that they can rely on their online Avatars to make them acceptable and welcome, they no more found it necessary to seek for social acceptance outside of the virtual world.

\section{Limitations and Future Directions}

The study limits itself with only one personality variable namely, locus of control. Further research should take into account other personality variables like extraversion, agreeableness, emotional stability, conscientiousness, self efficacy, self esteem, and so on which may associate with the online behavior of individuals, and mental health and subjective well being of people. The study has a restrictive sample size of individuals above the age of 18 years. But in today's world a child is exposed to the vagaries of internet at a very young age and thus a study to understand the effect of the online flow experience on their individual attitude and persona also seems a prudent way for a further study. Given that if an understanding of their behavioral lacuna can be detected at an early age then a corrective measure can be taken to help them as at an early age an individual is more acceptable and susceptible to change and with age the flexibility to accept change weakens. A further study can be done to categorically understand the effect of online flow experience, depression, subjective happiness and satisfaction with life in males and females separately.

Future research should take into account the limitation of this study in order to advance our knowledge. It would help us to get a richer insight into the behaviour of individuals in real and virtual world.

\section{References}

[1] J. Morahan-Martin, and P. Schumacher, "Loneliness and Social Uses of the Internet," Computers in Human Behavior, vol. 19, pp. 659-671, 2003.

[2] J. B. Rotter, "Generalized expectancies for internal versus external control of reinforcement," Psychological Monographs, vol. 80, pp. 1-28, 1966.

[3] M. Inozu, O. Yorulmaz, and S. Terzi, "Locus of control in obsessive-compulsive (OC) and depression symptoms: The moderating effect of externality on obsessive-related control beliefs in OC symptoms," Behaviour Change, vol. 29, pp. 148-163, 2012.

[4] A. Richardson, T. Field, R. Newton, and D. Bendell, "Locus of control and prenatal depression," Infant Behavior and Development, vol. 35, pp. 662-668, 2012. 
[5] E. Diener, E. Suh, R. E. Lucas, and H. L. Smith, "Subjective well-being: three decades of progress," Psychological Bulletin, vol. 125, pp. 276-302, 1999.

[6] T. C. Pannell, and A. F. Claxton, "Happiness, Creative Ideation, and Locus of Control," Creativity Research Journal, vol. 20, pp. 67-71, 2008.

[7] S. Popova, "Locus of Control - Predictor of Health and Subjective Well-Being," European Medical, Health and Pharmaceutical Journal, vol. 4, pp. 47-52, 2012.

[8] E. Diener, "Subjective Well-Being," Psychological Bulletin, vol. 95, pp. 542-575, 1984.

[9] A. Enkvist, H. Ekstrom, and S. Elmstahl, "What factors affect life satisfaction (LS) among the oldest-old?," Archives of Gerontology and Geriatrics, vol. 54, pp. 140-145, 2012.

[10] K. Srivastava, A. Shukla, and N. K. Sharma, "Online Flow Experiences: The Role of Need for Cognition, Self-Efficacy, and Sensation Seeking Tendency," IJBIT, vol. 3, pp. 93-100, 2010 .

[11] M. Csikszentmihalyi, Beyond boredom and anxiety., Jossey-Bass: San Francisco, 1977.

[12] D. L. Hoffman, and T. P. Novak, "Marketing in Hypermedia Computer-Mediated Environments: Conceptual Foundations," Journal of Marketing, vol. 60, pp. 50-68, 1996.

[13] K. Chak, and L. Leung, "Shymess and locus of controlas predictors of internet addiction and internet use," Cyberpsychology and Behaviour, vol. 7, pp. 559-570, 2004.

[14] H. Meltzer, P. Bebbington, M. S. Dennis, R. Jenkins, S. McManus, and T. S. Feelings of loneliness among adults with mental disorder," Social Psychiatry and Psychiatric Epidemiology, vol. 48, pp. 5-13, 2013.

[15] C. R. Victor, and K. Yang, "The prevalence of loneliness among adults: a case study of the United Kingdom," The Journal of psychology, vol. 146, pp. 85-104, 2012.
[16] R. Aylaz, U. Akturk, B. Erci, H. Ozturk, and H. Asian, "Relationship between depression and loneliness in elderly and examination of influential factors," Archives of Gerentology and Geriatrics, vol. 55, pp. 548-554, 2012.

[17] J. F. Schumaker, J. D. Shea, M. M. Monfries, and G. Groth-Marnat, "Loneliness and Life Satisfaction in Japan and Australia," The Journal of Psychology, vol. 127, pp. 65-71, 2010 .

[18] M. M. Y. Tse, A. M. H. Wong, and V. T. C. Wan, "Happiness among community-dwelling older persons: Is it related to pain and loneliness?," Journal of Pain Management, vol. 5, pp. 163-175, 2012.

[19] M. Durak, and E. Senol-Durak, "Psychometric qualities of the ucla loneliness scale-version 3 as applied in a Turkish culture," Educational Gerentology, vol. 36, pp. 988-1007, 2012.

[20] A. R. Ronaka, A. Taanila, M. Koiranen, V. Sunnari, and A. Rautio, "Associations of deliberate self-harm with loneliness, self-rated health and life satisfaction in adolescence: Northern Finland Birth Cohort 1986 study,” International Journal of Circumpolar Health, vol. 72, 2012.

[21] A. M. Fernandez-Alonso, M. Trabalon-Pator, C. Vara, P. Chedraui, and F. R. Perez-Lopez, "Life satisfaction, loneliness and related factors during female midlife," Maturitas, vol. 72, pp. 88-92, 2012.

[22] M. Csikszentmihalyi, Beyond boredom and anxiety, Jossey-Bass: San Francisco, 1975.

[23] R. Carden, and S. Rettew, "Internet chat room use, satisfaction with life and loneliness," Psychological Reports, vol. 98, pp. 121-122, 2006.

[24] I. Stepanikova, N. H. Nie, and X. He, "Time on the Internet at home, loneliness, and life satisfaction: Evidence from panel time-diary data," Computers in Human Behavior, vol. 26, pp. 329-338, 2010. 